\title{
Lupin kernel fibre foods improve bowel function and beneficially modify some putative faecal risk factors for colon cancer in men
}

\author{
Stuart K. Johnson*, Veronica Chua, Ramon S. Hall and Amynta L. Baxter \\ School of Exercise and Nutrition Sciences, Faculty of Health and Behavioural Sciences, Deakin University, 221 Burwood Hwy, \\ Burwood, Victoria, 3125, Australia
}

(Received 22 April 2005 - Revised 30 September 2005 - Accepted 18 October 2005)

\begin{abstract}
Consumption of some dietary fibres may benefit bowel health; however, the effect of Australian sweet lupin (Lupinus angustifolius) kernel fibre (LKFibre) is unknown. The present study examined the effect of a high-fibre diet containing LKFibre on bowel function and faecal putative risk factors for colon cancer compared to a control diet without LKFibre. Thirty-eight free-living, healthy men consumed an LKFibre and a control diet for 1 month each in a single-blind, randomized, crossover study. Depending on subject energy intake, the LKFibre diet was designed to provide $17-30 \mathrm{~g} / \mathrm{d}$ fibre (in experimental foods) above that of the control diet. Bowel function self-perception, frequency of defecation, transit time, faecal output, $\mathrm{pH}$ and moisture, faecal levels of SCFA and ammonia, and faecal bacterial $\beta$-glucuronidase activity were assessed. In comparison to the control diet, the LKFibre diet increased frequency of defecation by 0.13 events/d $(P=0 \cdot 047)$, increased faecal output by $21 \%(P=0 \cdot 020)$ and increased faecal moisture content by $1.6 \%$ units $(P=0.027)$, whilst decreasing transit time by $17 \%(P=0.012)$ and decreasing faecal pH by 0.26 units $(P<0.001)$. Faecal butyrate concentration was increased by $16 \%(P=0.006)$, butyrate output was increased by $40 \%(P=0.002)$ and $\beta$-glucuronidase activity was lowered by $1.4 \mu \mathrm{mol} / \mathrm{h}$ per $\mathrm{g}$ wet faeces compared to the control diet $(P<0 \cdot 001)$. Addition of LKFibre to the diet incorporated into food products improved some markers of healthy bowel function and colon cancer risk in men.
\end{abstract}

Lupin: Dietary fibre: Legume: Bowel function: Faeces: SCFA

Observations that populations consuming high-fibre diets had lower death rates from colon cancer led Burkitt to hypothesise that increased dietary fibre intake leads to a reduced risk of colon cancer (Burkitt, 1969). Some recent epidemiological studies have supported this hypothesis (Bingham et al. 2003; Peters et al. 2003), while others have not (Fuchs et al. 1999; Pietinen et al. 1999; Flood et al. 2002). Inconsistencies in study findings may be partly a result of the heterogeneity of the chemical nature and physicochemical properties of dietary fibre. Dietary fibres from different plant sources often demonstrate unique physicochemical properties (Lupton, 2000) that are influential in determining the effect of the dietary fibre on the chemical and physiological events in the colon that impact on colon cancer risk.

Depending on the plant source, dietary fibre may result in increased faecal bulk (Burkitt et al. 1972; Cummings et al. 1992), increased faecal moisture content (Wrick et al. 1983) and reduced intestinal transit time (Burkitt et al. 1972; Wrick et al. 1983). These changes to bowel function are typical of insoluble fibre sources such as outer bran layers of cereals (Bach Knudsen et al. 1997) and are considered to reduce colon cancer risk since they decrease exposure of colonocytes to potential carcinogens that may be present in the bolus (Cummings et al. 1992). Soluble fibres, for example pectin, are generally considered to have less effect on faecal bulking and transit time than insoluble fibres (Bach Knudsen et al. 1997) because they are more readily lost in the colon through fermentation by resident bacteria. The fermentation process, however, produces SCFA (Cummings \& Macfarlane, 1991), of which butyrate has been linked to reduction in colon cancer risk. Butyrate is the preferred source of energy for colonocytes (Cummings \& Branch, 1986) and is able to reduce risk of malignant changes through regulation of colonocyte differentiation (Hague et al. 1995; Cummings \& Macfarlane, 1997). Bacterial fermentation of dietary fibre may also increase utilization of ammonia by bacteria (Weber et al. 1987). Ammonia has been implicated in tumour promotion, increased cell proliferation, and alterations to cell morphology and DNA synthesis (Visek, 1978; Lin \& Visek, 1991). The combination of elevated SCFA and lowered ammonia production due to consumption of some forms of dietary fibre can lead to lowered colonic pH (Hague et al. 1995). Lowering colonic $\mathrm{pH}$ may be protective against colon cancer since increasing colonic $\mathrm{pH}$ promotes carcinogen formation from bacterially degraded bile acids and cholesterol (Thornton, 1981).

The chemical nature of substrates available for fermentation can influence the profile of bacterial species present in the colon. Consequently, dietary fibres from different sources may differentially modify bacterial profiles and the levels of species-specific catabolic enzymes and potentially carcinogenic bacterial metabolites in the colon (Cook \& Sellin, 
1998). There is some evidence that lupin kernel fibre (LKFibre) may beneficially modify colonic microflora populations (Smith et al. 2005). The bacterial enzyme, $\beta$-glucuronidase, is considered deleterious to colon cancer risk since this enzyme hydrolyses glucuronic acid conjugates manufactured in the liver from toxic metabolites. De-conjugation in the colon releases the potentially carcinogenic parent compounds and thus may increase the likelihood of tumour initiation (Gill \& Rowland, 2002).

LKFibre is a novel food ingredient containing both soluble and insoluble fractions (Hall et al. 2005). It is extracted from the kernel of Australian sweet lupin (Lupinus angustifolius), a legume grown in large quantities in Australia and considered to be underutilized as a human food source (Petterson, 1998). Currently, it is being used mainly as an animal feed. The dietary fibre content of Australian sweet lupin kernels is higher than that of most other legumes, making up approximately $40 \%$ of the kernel weight (Johnson \& Gray, 1993; Petterson, 1998; Guillon \& Champ, 2002). LKFibre has shown potential for the manufacture of palatable, fibre-enriched products such as baked goods and pasta (Clark \& Johnson, 2002).

No human studies investigating the effect of LKFibre on bowel function or faecal putative risk factors for colon cancer have been reported. The aim of the current study was to compare the effect of a high-fibre diet incorporating LKFibre with a lower-fibre diet without LKFibre on bowel function and faecal putative risk factors for colon cancer in healthy men.

\section{Methods}

\section{Participants}

As part of a larger study also investigating the effect of LKFibre on blood lipids, glucose and insulin (Hall et al. 2005), forty-four healthy male subjects were recruited through newspaper articles, radio announcements, posted notices and direct personal communication in Melbourne, Australia. After giving written informed consent, volunteers were screened for suitability using a health questionnaire. Exclusion criteria were cigarette smoking; an allergy to any food ingredients used in the study or to legumes such as soya and peanuts; a history of gastrointestinal problems, CVD or diabetes; and use of medications known to affect lipid and carbohydrate metabolism. Thirty-eight subjects completed the study with a mean age of 41 (SEM 2; range 24-64) years and mean BMI of 26.7 (SEM 0.5 ; range $20 \cdot 9-33 \cdot 5$ ) $\mathrm{kg} / \mathrm{m}^{2}$.

Of the six subjects who did not complete the study, two discontinued after 1 week of the LKFibre diet due to feelings of abdominal bloating, and the remainder left at various stages of the study due to personal reasons. The study was conducted according to the Helsinki Declaration of 1975, as revised in 2000. Deakin University Ethics Committee granted approval for the study.

\section{Study design}

A single-blind, randomized, crossover, dietary intervention design in free-living subjects was used in the present study. It consisted of two semi-controlled diets equal in total energy to each subject's habitual diet, one a high-fibre diet including seven LKFibre-containing experimental foods, and the other a lower-fibre control diet of otherwise equivalent nutritional profile but with the seven placebo foods containing no LKFibre. Subjects were block randomized, in groups of four, to one of the diets (LKFibre or control) for a period of $28 \mathrm{~d}$, then returned to their habitual diet for a washout period of a minimum of $28 \mathrm{~d}$ before undertaking the alternate $28 \mathrm{~d}$ test diet. An equal number of subjects ( $n$ 19) completed each diet order.

A $4 \mathrm{~d}$ weighed food record was completed prior to the intervention phase of the study and again during the second week of each intervention. Subjects completed questionnaires assessing their self-perception of bowel function on day 18 of each intervention at which time effects due to the diets should be well established. On the mornings of days 23, 24 and 25 of each intervention, subjects swallowed twenty radio-opaque rings (of a different shape on each day) (TRANSCAP; Ninewells Hospital and Medical School, Dundee, UK) and recorded the time of swallowing. All faeces passed during days 24,25 and 26 of each intervention were collected by the subject into containers that were initially stored in insulated boxes containing solid carbon dioxide ('dry-ice'). Subjects recorded the time and date of each defecation event. Collected faecal samples were transported to Deakin University each day by the researchers, weighed and then stored at $-20^{\circ} \mathrm{C}$. Faecal samples remained frozen throughout and were received at the laboratory between 1 and $25 \mathrm{~h}$ after defecation. Mouth to anus transit time was calculated from the number and types of markers detected by a single X-ray of the first stool passed on day 26 (Birkett et al. 1997).

\section{Experimental foods}

The LKFibre (Table 1) was manufactured by Food Science Australia (Werribee, Victoria, Australia). The LKFibre and control experimental foods (bread, muffin, chocolate brownie, chocolate milk drink, toasted muesli, pasta and instant mashed potato) were manufactured by George Weston Foods (Enfield, New South Wales, Australia). The LKFibre incorporation rates in the experimental foods have been described elsewhere (Hall et al. 2005). The nutrient composition of the experimental foods was directly analysed by standard procedures of the Association of Official Analytical Chemists (1990).

Table 1. Compositional data of lupin kernel fibre ingredient

\begin{tabular}{lc}
\hline & Amount \\
\hline Energy $(\mathrm{kJ} / 100 \mathrm{~g}) \ddagger$ & 883 \\
Protein $(\mathrm{g} / 100 \mathrm{~g}) \S$ & 5.9 \\
Available carbohydrate $(\mathrm{g} / 100 \mathrm{~g}) \S$ & $<0 \cdot 1$ \\
Total dietary fibre $(\mathrm{g} / 100 \mathrm{~g}) \S$ & 88.0 \\
Soluble dietary fibre $(\mathrm{g} / 100 \mathrm{~g}) \S$ & 44.7 \\
Insoluble dietary fibre $(\mathrm{g} / 100 \mathrm{~g}) \S$ & $43 \cdot 1$ \\
Fat $(\mathrm{g} / 100 \mathrm{~g}) \S$ & $2 \cdot 1$ \\
\hline
\end{tabular}

$\ddagger$ Calculated using Atwater factors and assuming dietary fibre energy is equivalent to $8 \mathrm{~kJ} / \mathrm{g}$.

$\S$ Analysis based on the methods of the Association of Official Analytical Chemists (1990). 


\section{Dietary intervention}

The dietary intervention has been described in detail elsewhere (Hall et al. 2005). In brief LKFibre and control diets equivalent in macronutrient composition, with the exception of dietary fibre, were prescribed to each subject to match their habitual energy intake as determined by a $4 \mathrm{~d}$ weighed food record. To help ensure dietary compliance, the dietary fibre level in each subject's prescribed diet was stratified based on the total prescribed energy. The LKFibre experimental foods or their respective controls were incorporated into $3 \mathrm{~d}$ rotating menus (Hall et al. 2005). An example of $1 \mathrm{~d}$ of this menu is given in Table 2. Detailed written instructions on dietary protocol as well as counselling on a weekly basis by a nutritionist were provided to help maximize compliance. Subjects were instructed to avoid legumes, high-fat foods and known lipid-modifying foods such as spreads containing phytosterol and fermented foods such as yoghurt.

\section{Dietary assessment}

Prior to commencement of the study, each participant was provided with a set of electronic scales, measuring cups and a graduated measuring jug, then trained by researchers in the accurate measurement of the weight or volume of food and drink. Participants were also provided with a food diary that contained detailed instructions on how to record, in as much detail as possible, every item that they ate or drank, how the item was prepared and its accurately measured weight or volume. Subjects completed a $4 \mathrm{~d}$ weighed food record (that

Table 2. An example of $1 \mathrm{~d}$ of the $3 \mathrm{~d}$ repeating menu for a $12 \mathrm{MJ} / \mathrm{d}$ diet

\begin{tabular}{|c|c|}
\hline Breakfast & $\begin{array}{l}200 \mathrm{ml} \text { orange juice } \\
60 \mathrm{~g} \text { control or LKFibre muesli } \\
2 \times 30 \mathrm{~g} \text { slices control or LKFibre bread } \\
10 \mathrm{~g} \text { polyunsaturated margarine } \neq \\
20 \mathrm{~g} \text { jam }\end{array}$ \\
\hline Lunch & $\begin{array}{l}2 \times 30 \mathrm{~g} \text { slices control or LKFibre bread } \neq \\
10 \mathrm{~g} \text { polyunsaturated margarine } \neq \\
30 \mathrm{~g} \text { cheese } \\
10 \mathrm{~g} \text { lettuce } \\
30 \mathrm{~g} \text { tomato } \\
20 \mathrm{~g} \text { cucumber } \\
57 \mathrm{~g} \text { control or LKFibre chocolate } \\
\text { drink powder } ¥\end{array}$ \\
\hline Dinner & $\begin{array}{l}200 \mathrm{~g} \text { lean meat } \\
5 \mathrm{ml} \text { vegetable oil } \neq \\
35 \mathrm{~g} \text { control or LKFibre instant } \\
\text { potato powder } \\
150 \mathrm{~g} \text { mixed vegetables } \\
200 \mathrm{~g} \text { canned fruit } \\
100 \mathrm{~g} \text { ice cream }\end{array}$ \\
\hline $\begin{array}{l}\text { Snacks and daily } \\
\text { allowances }\end{array}$ & $\begin{array}{l}2 \times 80 \mathrm{~g} \text { control or LKFibre chocolate } \\
\text { brownies } \ddagger \\
500 \mathrm{ml} \text { low fat milk } \\
\text { Ad libitum tea, coffee } \\
\text { Sugar in beverages } \S \\
375 \mathrm{ml} \text { soft drink } \\
2 \text { standard drinks of alcohol } \\
30 \mathrm{~g} \text { condiments } \\
100 \mathrm{ml} \text { cordial base } \|\end{array}$ \\
\hline
\end{tabular}

LKFibre, lupin kernel fibre.

$\ddagger$ Supplied by researchers.

$\S$ Sugar allowance was prescribed at habitual intake levels and kept constant on both interventions.

\| LKFibre diet only. included one weekend day) of their habitual diet prior to commencement of the interventions and during the second week of each intervention. After completion, researchers discussed each food record with the participant, reviewed the information and discussed any unclear or missing information with the participant in order to minimize inaccuracies commonly associated with weighed food records. Weighed food records were analysed using FoodWorks version 3.01, build 472 (Xyris Software, Brisbane, Queensland, Australia), which incorporates the AusNut database (All Foods, Revision 14). The database was supplemented with the direct analysis of the experimental foods and manufacturers' information for foods not found on the database.

\section{Bowel function questionnaires}

Subjects were interviewed weekly throughout the study period to obtain a subjective assessment of bowel function and wellbeing, and were asked to record any unusual gastrointestinal events. On day 18 of each intervention period, the following subjective assessments of bowel function as experienced over the previous few days were assessed by self-administered questionnaires: (1) stool form by visual assessment using the Bristol Stool Form Scale (type $1=$ 'separate hard lumps, like nuts (hard to pass)' through to type $7=$ 'watery, no solid pieces, entirely liquid') (O’Donnell et al. 1990); (2) ease of defecation $(15 \mathrm{~cm}$ line scale: left-hand anchor $=$ 'extremely difficult', mid-point anchor = 'same as usual', right-hand anchor = 'extremely easy'); (3) frequency of defecation $(15 \mathrm{~cm}$ line scale: left-hand anchor $=$ 'far less often than usual', mid-point anchor $=$ 'same as usual', right-hand anchor = 'much more often than usual'); (4) level of flatulence $(15 \mathrm{~cm}$ line scale: left-hand anchor $=$ 'far less than usual', mid-point anchor = 'same as usual', right-hand anchor = 'much more than usual'); and (5) general bowel health $(15 \mathrm{~cm}$ line scale: left-hand anchor $=$ 'far worse than usual', mid-point anchor $=$ 'same as usual', right-hand anchor $=$ 'much better than usual'). Responses to the Bristol Stool Form Scale were enumerated as the number corresponding to the selected stool type. For the line scales, subjects were asked to mark a position anywhere along the scales that matched their perception. The ratings were then converted to a numerical score based on distance in centimetres (to one decimal place) from the far left anchor of the scale.

\section{Faecal analysis}

The frozen $3 \mathrm{~d}$ faecal collections were pooled per subject then thawed rapidly in a warm water bath. After manual homogenization, $\mathrm{pH}$ was immediately determined in three different sites using a protein-resistant $\mathrm{pH}$ glass electrode (Orion Research Incorporated, Boston, MA, USA). For measurement of SCFA, $1.5 \mathrm{~g}$ pooled faeces was immediately diluted 1:3 with $0.9 \%$ saline and stored at $-20^{\circ} \mathrm{C}$ until analysis. Moisture content of pooled faeces was determined by weight loss on drying overnight to a constant weight in a rotary vacuum evaporator (Hetovac model VR-1/120/240; Heto Laboratory Equipment -High Technology of Scandinavia, Birkerød, Denmark). Representative sub-samples of the remaining pooled faeces were immediately frozen at $-20^{\circ} \mathrm{C}$ until required for determination of ammonia and bacterial enzyme activity. 
To measure SCFA, the previously prepared faecal saline suspensions were rapidly thawed in warm water and dispersed by vortexing with glass beads. After centrifugation at $1200 \mathrm{~g}$ for $10 \mathrm{~min}$ at $4^{\circ} \mathrm{C}, 200 \mu \mathrm{l}$ supernatant was mixed with $20 \mu \mathrm{l}$ orthophosphoric acid (1:5 solution in distilled water; to precipitate contaminating material) and $20 \mu \mathrm{l}$ methylvaleric acid (32 mM, internal standard). Samples were vortexed and then centrifuged at $1200 \mathrm{~g}$ for $15 \mathrm{~min}$ at $4^{\circ} \mathrm{C}$. The supernatant was then used for analysis. A $1 \mu \mathrm{l}$ sample of the final supernatant was analysed by GC with flame ionization detection (Phillips et al. 1995) using a Varian Model 3700 gas chromatogram (Varian Associates, Palo Alto, CA, USA) with a nucol fused silica capillary column $(30 \mathrm{~m} \times 0.25 \mathrm{~mm}$ internal diameter, $0.25 \mathrm{~mm}$ thickness; Supelco, Bellefonte, PA, USA).

For determination of ammonia, $0.5 \mathrm{~g}$ thawed pooled sample was immediately diluted 1:20 with $3 \%$ TCA, vortexed with glass beads, then centrifuged at $500 \mathrm{~g}$ for $10 \mathrm{~min}$ at $4^{\circ} \mathrm{C}$ (Lin $\&$ Visek, 1991). The resulting supernatant was filtered, diluted 1:2 with distilled water (Birkett et al. 1996) and used to determine faecal ammonia concentration using the Berthelot's indophenol colour reaction (Di Giorgio, 1974).

Faecal $\beta$-glucuronidase activity was determined using the deconjugated phenolphthalein glucuronic acid colour reaction based on the procedure of McIntosh et al. (2003), in which the $\beta$-glucuronidase enzyme present in the faecal sample deconjugates phenolphthalein from the phenolphthalein-glucuronic acid conjugate reagent. Thus, the amount of phenolphthalein released is representative of the enzyme activity. Pooled thawed faeces $(3 \mathrm{~g})$ were immediately homogenized (IKA T25 Basic Ultra-turrax; IKA Works Asia SDN BHD, Selangor, Malaysia) in $7 \mathrm{ml} \mathrm{PBS}$, pH 7.0, then centrifuged at $10000 \mathrm{~g}$ for $20 \mathrm{~min}$ at $4^{\circ} \mathrm{C}$. Following this, $100 \mu \mathrm{l}$ of the resulting supernatant were added to an equal volume of phenolphthalein-glucuronic acid conjugate reagent in $0.8 \mathrm{ml}$ PBS and incubated at $37^{\circ} \mathrm{C}$ for $60 \mathrm{~min}$ (Jenab et al. 1999) for enzymatic activity to occur. Enzyme activity was terminated by the addition of alkaline glycine solution and water to a volume of $6 \mathrm{ml}$. Phenolphthalein colour was developed for $10 \mathrm{~min}$ and the absorbance was measured at $540 \mathrm{~nm}$. $\beta$-Glucuronidase activity was expressed as $\mu \mathrm{mol}$ phenolphthalein released per $\mathrm{g}$ wet weight per $\mathrm{h}$ as determined from a phenolphthalein standard curve.

\section{Statistical analysis}

The normality of the study data was evaluated using Kolmogorov-Smirnov tests. A paired samples $t$ test or a two-related sample non-parametric test (Wilcoxon signed ranks test) for non-normal data was used to compare the effect of dietary intervention on each variable using SPSS software, version 11.5 (SPSS Inc., Chicago, IL, USA). In all analyses, $P<0.050$ was considered significant. Data are expressed as means and their standard errors.

\section{Results}

\section{Compliance, food consumption and body weight}

During weekly counselling sessions, subjects who completed the study did not report any major concerns regarding either dietary regime. The self-reported dietary intakes during the preexperimental, LKFibre and control diets have been published previously elsewhere (Hall et al. 2005). In brief, the LKFibre and control diets were generally well-balanced for energy and macronutrients, with the exception of dietary fibre levels (by design), which were on average $22.2 \mathrm{~g} / \mathrm{d}$ higher $(P<0.001)$ on the LKFibre than on the control diet. In addition, a slightly but significantly lower (2.9\% of energy, $P=0.001)$ mean available carbohydrate level and a slightly but significantly higher $(0.8 \%$ of energy, $P=0.021)$ mean protein level was recorded during the LKFibre diet. No differences in body weight $(P>0.05)$ were seen between the two diets.

\section{Perceptive ratings of bowel function}

Data on subjects' perceptive ratings of bowel function are shown in Table 3. Perceptions of frequency and ease of defecation did not differ significantly between the LKFibre and the control diets. A significantly higher perception of flatulence level on the LKFibre diet than the control diet was observed $(P<0.001)$, but the perceptions of bowel health on the two diets were not significantly different. Appearance of stools, as self-evaluated by the Bristol Stool Form Scale, did not significantly differ between the two diets.

\section{Frequency of defecation, transit time, faecal output, $\mathrm{pH}$ and} moisture

Frequency of defecation, transit time, faecal output, $\mathrm{pH}$ and moisture data are shown in Table 4. A small but significant increase $(0.13$ events/d, $P=0.047)$ in defecation events was observed during the LKFibre diet compared to the control diet. Faecal output $(\mathrm{g} / \mathrm{d})$ was significantly higher $(21 \%, P=0.020)$ during the LKFibre diet, representing an increase of $1.6 \mathrm{~g}$ faeces/g additional dietary fibre contributed by LKFibre. Mouth to anus transit time (h) was significantly shorter (17\%, $P=0.012)$ during the LKFibre diet than during the control diet. Faecal $\mathrm{pH}$ was significantly lower $(0.26$ units, $P<0.001)$ and faecal moisture content significantly higher ( $1.6 \%$ units, $P=0 \cdot 027$ ) during the LKFibre diet than during the control diet.

Table 3. Effect of lupin kernel fibre (LKFibre) diet on perceptive ratings of bowel function $(n 38) \ddagger$

\begin{tabular}{|c|c|c|c|c|}
\hline & \multicolumn{4}{|c|}{ Diet } \\
\hline & \multicolumn{2}{|c|}{ LKFibre } & \multicolumn{2}{|c|}{ Control } \\
\hline & Mean & SEM & Mean & SEM \\
\hline Frequency of defecation§ & $7 \cdot 9$ & 0.4 & $7 \cdot 6$ & 0.3 \\
\hline Ease of defecation\| & 8.5 & 0.5 & $8 \cdot 0$ & 0.3 \\
\hline Flatulence levelq & $9 \cdot 9^{\star \star \star}$ & 0.3 & $8 \cdot 3$ & 0.3 \\
\hline Bowel health $\ddagger \ddagger$ & $7 \cdot 4$ & 0.4 & $7 \cdot 9$ & 0.2 \\
\hline Bristol Stool Form Scale§§ & $3 \cdot 8$ & 0.2 & 3.7 & 0.1 \\
\hline
\end{tabular}

Mean value was significantly different from that of the control group: ${ }^{* \star \star} P<0.001$ (Wilcoxon signed ranks test).

f For details of diets and procedures, see p. 373

$\$ 15 \mathrm{~cm}$ line scale: left-hand anchor = 'far less often than usual', mid-point anchor $=$ 'same as usual', right-hand anchor $=$ 'much more often than usual'.

$\| 15 \mathrm{~cm}$ line scale: left-hand anchor = 'extremely difficult', mid-point anchor = 'same as usual', right-hand anchor = 'extremely easy'.

I $15 \mathrm{~cm}$ line scale: left-hand anchor = 'far less than usual', mid-point anchor = 'same as usual', right-hand anchor = 'much more than usual'.

$\ddagger \ddagger 15 \mathrm{~cm}$ line scale: left-hand anchor = 'far worse than usual', mid-point anchor = 'same as usual', right-hand anchor = 'much better than usual'.

$\S \S 1=$ 'separate hard lumps, like nuts (hard to pass)' through to $7=$ 'watery, no solid pieces, entirely liquid'. 
Table 4. Effect of lupin kernel fibre (LKFibre) diet on frequency of defecation, transit time, faecal output, $\mathrm{pH}$ and moisture ( $n$ 38)‡

\begin{tabular}{lccccc}
\hline & \multicolumn{4}{c}{ Diet } \\
\cline { 2 - 3 } & \multicolumn{2}{c}{ LKFibre } & & \multicolumn{2}{c}{ Control } \\
\cline { 2 - 3 } \cline { 5 - 6 } & Mean & SEM & & Mean & SEM \\
\hline $\begin{array}{l}\text { Frequency of defecation } \\
\quad \text { (events/d) }\end{array}$ & $1.46^{*}$ & 0.1 & & 1.33 & 0.1 \\
Faecal output (g/d) & $208 \dagger$ & 14 & & 172 & 11 \\
Transit time (h) & $36.9 \dagger$ & 1.9 & & 44.3 & 2.8 \\
Faecal pH & $6.34 \dagger \dagger \dagger$ & 0.07 & 6.60 & 0.08 \\
Faecal moisture content (\%) & $73.7 \dagger$ & 0.87 & & 72.1 & 0.88 \\
\hline
\end{tabular}

Mean value was significantly different from that of the control group: ${ }^{*} P<0.05$ (Wilcoxon signed ranks test).

Mean values were significantly different from that of the control group: $\dagger P<0.05$ (paired samples $t$ test)

Mean value was significantly different from that of the control group: $\uparrow+\uparrow P<0.001$ (paired samples $t$ test)

‡For details of diets and procedures, see p. 373.

\section{SCFA in faeces}

Differences in the SCFA levels of the faeces were seen between the LKFibre and the control diets (Table 5). A significantly higher concentration ( $\mu \mathrm{mol} / \mathrm{g}$ wet faeces; $19 \%$, $P=0.001)$ and daily output (mmol $/ \mathrm{d} ; 44 \%, P<0.001)$ of total SCFA and a significantly higher concentration $(22 \%$, $P<0.001)$ and daily output $(50 \%, P<0.001)$ of acetate were found on the LKFibre diet compared to the control diet. A trend towards a higher concentration (21\%, $P=0.091$, Wilcoxon signed ranks test) and a significantly higher output $(42 \%, P=0.002)$ of propionate was observed during the LKFibre diet than during the control diet. A significantly higher butyrate concentration $(16 \%, P=0.006)$ and output ( $40 \%, P=0.002$ ) was observed during the LKFibre diet than during the control diet. A significantly higher valerate output $(21 \%, P=0.030)$ but no significant difference in concentration was found for the LKFibre compared to the control diet. No significant effect of LKFibre was observed for the concentration or output of isobutyrate or isovalerate. Compared to the control diet, the LKFibre diet produced a significant increase in the molar ratio (\% of total) of acetate ( $1.7 \%$ units) and a significant decrease in the molar ratios of isobutyrate $(0.4 \%$ units, $P<0.001)$, isovalerate $(0.7 \%$ units, $P<0.001)$ and valerate $(0.5 \%$ units, $P<0.001)$. No significant differences between the molar ratios of propionate or butyrate during the LKFibre and control diets were observed.

\section{Ammonia concentration and $\beta$-glucuronidase activity in faeces}

There was no significant difference between the ammonia concentration of the faeces collected during the LKFibre diet and the faeces collected during the control diet ( $n$ 38; 61.4 (SEM 4.6) compared with 62.9 (SEM 3.8) $\mu \mathrm{mol} / \mathrm{g}$ wet faeces, respectively). During the LKFibre diet, faecal $\beta$-glucuronidase activity was significantly lower than during the control diet ( $n$ 38; 4.1 (SEM 0.5) compared with 5.5 (SEM $0.5) \mu \mathrm{mol} / \mathrm{h}$ per $\mathrm{g}$ wet faeces, respectively; $P<0.001$, paired samples $t$ test).
Table 5. Effect of lupin kernel fibre (LKFibre) diet on faecal SCFA ( $n$ 38)‡

\begin{tabular}{|c|c|c|c|c|}
\hline & \multicolumn{4}{|c|}{ Diet } \\
\hline & \multicolumn{2}{|c|}{ LKFibre } & \multicolumn{2}{|c|}{ Control } \\
\hline & Mean & SEM & Mean & SEM \\
\hline \multicolumn{5}{|l|}{ Total SCFA } \\
\hline ( $\mu \mathrm{mol} / \mathrm{g}$ wet faeces) & $128 \cdot 7 \dagger \dagger$ & $5 \cdot 5$ & $108 \cdot 6$ & $5 \cdot 4$ \\
\hline$(\mathrm{mmol} / \mathrm{d})$ & 28.3††† & $2 \cdot 7$ & $19 \cdot 7$ & 1.8 \\
\hline \multicolumn{5}{|l|}{ Acetate } \\
\hline ( $\mu \mathrm{mol} / \mathrm{g}$ wet faeces) & 78.9††† & 3.5 & $64 \cdot 7$ & 3.4 \\
\hline$(\mathrm{mmol} / \mathrm{d})$ & 17.7††† & $1 \cdot 8$ & $11 \cdot 8$ & $1 \cdot 1$ \\
\hline (\% of total) & $61 \cdot 3^{*}$ & 0.8 & $59 \cdot 6$ & 0.9 \\
\hline \multicolumn{5}{|l|}{ Propionate } \\
\hline ( $\mu \mathrm{mol} / \mathrm{g}$ wet faeces) & $21 \cdot 2$ & 1.9 & $17 \cdot 6$ & $1 \cdot 1$ \\
\hline$(\mathrm{mmol} / \mathrm{d})$ & $4 \cdot 4^{\star *}$ & 0.5 & $3 \cdot 1$ & 0.3 \\
\hline (\% of total) & $16 \cdot 1$ & 0.9 & $16 \cdot 2$ & 0.5 \\
\hline \multicolumn{5}{|l|}{ Isobutyrate } \\
\hline ( $\mu \mathrm{mol} / \mathrm{g}$ wet faeces) & $1 \cdot 8$ & 0.1 & $2 \cdot 0$ & 0.1 \\
\hline$(\mathrm{mmol} / \mathrm{d})$ & 0.34 & 0.02 & 0.32 & 0.03 \\
\hline (\% of total) & 1.6††† & $0 \cdot 1$ & $2 \cdot 0$ & 0.2 \\
\hline \multicolumn{5}{|l|}{ Butyrate } \\
\hline ( $\mu \mathrm{mol} / \mathrm{g}$ wet faeces) & $21.6 † \dagger$ & $1 \cdot 2$ & $18 \cdot 7$ & 1.4 \\
\hline$(\mathrm{mmol} / \mathrm{d})$ & $4 \cdot 9^{\star \star}$ & 0.6 & 3.5 & 0.5 \\
\hline (\% of total) & $16 \cdot 7$ & 0.6 & $16 \cdot 5$ & 0.7 \\
\hline \multicolumn{5}{|l|}{ Isovalerate } \\
\hline ( $\mu \mathrm{mol} / \mathrm{g}$ wet faeces) & $2 \cdot 6$ & $0 \cdot 2$ & $2 \cdot 8$ & 0.2 \\
\hline$(\mathrm{mmol} / \mathrm{d})$ & 0.46 & 0.03 & 0.45 & 0.04 \\
\hline (\% of total) & $2 \cdot 2^{\star \star \star}$ & $0 \cdot 2$ & 2.9 & 0.3 \\
\hline \multicolumn{5}{|l|}{ Valerate } \\
\hline ( $\mu \mathrm{mol} / \mathrm{g}$ wet faeces) & $2 \cdot 6$ & 0.2 & $2 \cdot 7$ & 0.2 \\
\hline$(\mathrm{mmol} / \mathrm{d})$ & $0.52 \dagger$ & 0.05 & 0.43 & 0.04 \\
\hline (\% of total) & $2 \cdot 1^{\star \star \star}$ & 0.2 & $2 \cdot 6$ & 0.2 \\
\hline
\end{tabular}

Mean value was significantly different from that of the control group (Wilcoxon signed ranks test): ${ }^{\star} P<0.05,{ }^{* \star} P<0.01,{ }^{* * *} P<0.001$.

Mean value was significantly different from that of the control group (paired samples $t$ test): $† P<0.05, \dagger \dagger P<0.01, \dagger^{\dagger}+P<0.001$

$\ddagger$ For details of diets and procedures, see p. 373 .

\section{Discussion}

The present study has demonstrated for the first time that the addition of LKFibre to the diet improves bowel function (frequency of defecation, faecal output, faecal moisture content, transit time) in healthy men. Similar beneficial changes to bowel function have been reported following the consumption of foods containing outer bran layers of cereal (Bach Knudsen et al. 1997). These beneficial effects of cereal bran have been attributed to the water-binding capacity of the fibre that remains unfermented in the colon (Bach Knudsen et al. 1997). In foods that contain both soluble and insoluble fibre fractions, such as rye bread (Gråsten et al. 2000), improved bowel function has also been linked to the formation of faecal biomass from fibre fermentation. LKFibre contains both soluble and insoluble fractions and has high water binding capacity (Turnbull et al. 2005). We observed both an increase in the moisture content of the faeces and evidence of colonic fermentation (flatulence, SCFA production) in the present study. These observations suggest that the improved bowel function was the result of a combination of increased faecal biomass due to fibre fermentation and high water binding by residual fibre. It has been suggested, based on epidemiological data, that when stool weight is over $200 \mathrm{~g} / \mathrm{d}$, colon cancer risk becomes low (Cummings et al. 1992). We observed that the addition of LKFibre to the diet resulted in 
an increase in mean stool weight from below $(172 \mathrm{~g} / \mathrm{d})$ to above $(208 \mathrm{~g} / \mathrm{d})$ this low-risk cut-off value. Wheat bran is considered to be one of the most effective faecal bulking agents (Cummings, 1986) and can result in an increase in faecal weight of $4.9 \mathrm{~g} / \mathrm{g}$ fibre (Cummings et al. 1996). The increase in faecal weight due to LKFibre addition in the present study was lower than that of wheat bran and more similar to that reported for resistant starches (Jenkins et al. 1998).

The present study provides evidence that subjects' perceptive ratings of bowel function were not generally modified by the addition of LKFibre to the diet, even at the high levels of LKFibre used (the possible exception being the two subjects who dropped out of the study due to abdominal bloating). A higher level of flatulence was perceived on the LKFibre diet. Nevertheless, in the subjects completing the study, it does not appear that this flatulence was perceived negatively since there was no difference in the perception of bowel health between the two diets.

A lower faecal $\mathrm{pH}$ was observed during the LKFibre diet than during the control diet, a finding that suggests a reduced colon cancer risk (MacDonald et al. 1978; Thornton, 1981; Malhotra, 1982). The difference in $\mathrm{pH}$ between the LKFibre and the control diets was of a similar magnitude to that previously observed for high-fibre wheat and rye diets compared to a low-fibre control diet (McIntosh et al. 2003). Interestingly, both the control and the LKFibre diets resulted in a faecal $\mathrm{pH}$ that is considered to be low-risk (MacDonald et al. 1978; Malhotra, 1982), possibly as a result of the relatively high levels of fibre present even in the control diet; therefore the physiological value of the small drop in $\mathrm{pH}$ due to the LKFibre that we observed is presently unknown.

The present study has provided the first evidence that the addition of LKFibre to the diet modifies levels of faecal SCFA. The higher levels of faecal total SCFA during the LKFibre diet appear to be due primarily to an increase in acetate levels. Similar results were reported after consumption of high levels of mixed vegetable fibre, which included pea fibre and soya polysaccharides (Fredstrom et al. 1994). The higher faecal butyrate concentration and daily output observed on the LKFibre diet suggests a reduction in colon cancer risk (Cummings \& Branch, 1986; Hague et al. 1995; Cummings \& Macfarlane, 1997). Slow colonic fermentation has been associated with increased butyrate synthesis (Nordgaard et al. 1995; Silvester et al. 1995). LKFibre, being a combination of soluble and insoluble fractions, may be fermented relatively slowly, thus accounting for the increased butyrate levels observed. The increased levels of faecal propionate we observed on addition of LKFibre to the diet, though of less direct importance to bowel health, may help to explain the previously reported cholesterol-lowering effect of this fibre of potential benefit to cardiovascular health that was found in the same cohort of subjects (Hall et al. 2005). One way in which fermentable fibres beneficially modify blood cholesterol levels is through an effect of propionate on liver cholesterol metabolism (Demigne et al. 1995; Wolever et al. 1995, 1996). In the present study, valerate and the branch-chained SCFA isobutyrate and isovalerate made up less than $10 \%$ of the total SCFA in the faeces. The addition of LKFibre to the diet did modify the levels of these minor SCFA, although the physiological relevance of these changes is currently unknown.

Consumption of LKFibre did not change faecal ammonia concentrations in the present study. Similar outcomes have been reported previously in studies using other fermentable carbohydrate sources such as transgalacto-oligosaccharides (Alles et al. 1999), rye (McIntosh et al. 2003) and some types of resistant starches (Silvester et al. 1997).

We observed that $\beta$-glucuronidase activity during the LKFibre diet was lower than such activity during the control diet. The present finding suggests the possibility of a reduced colon cancer risk (Gill \& Rowland, 2002), but the relevance to bowel physiology of the small drop in activity we observed is presently unknown. The reduction in $\beta$-glucuronidase activity was similar to that reported in studies using wholegrain wheat (McIntosh et al. 2003) and rye (Gråsten et al. 2000).

In conclusion, the present study has provided the first evidence that consumption of LKFibre by healthy men can beneficially affect bowel function and faecal parameters related to colon cancer risk. The present findings support the argument that this novel dietary fibre ingredient has a role to play in the maintenance of a healthy bowel.

\section{Acknowledgements}

We are grateful to Food Science Australia for manufacturing the LKFibre and to George Weston Foods for manufacturing the experimental food products and conducting microbiological and nutritional analysis of these foods. We thank Madeleine Ball for advice on the dietary design and Gwyn Jones for advice on faecal sample collection and analysis protocols. We are indebted to the study participants for their commitment to the study protocol. This research was supported by the Grains Research and Development Corporation, the Australian Research Council - Strategic Partnerships with Industry - Research and Training Scheme, the Department of Agriculture Western Australia and Deakin University.

\section{References}

Alles MS, Hartemink R, Meyboom S, Harryvan JL, Van Laere KMJ, Nagengast FM \& Hautvast JGAJ (1999) Effect of transgalactooligosaccharides on the composition of the human intestinal microflora and on putative risk markers for colon cancer. Am J Clin Nutr 69, 980-991.

Association of Official Analytical Chemists (1990) Official Methods of Analysis, 15th ed. Washington, DC: AOAC.

Bach Knudsen KE, Johansen HN \& Glitso V (1997) Rye dietary fibre and fermentation in the colon. Cereal Foods World 72, 690-694.

Bingham SA, Day NE, Luben R, et al. (2003) Dietary fibre in food and protection against colorectal cancer in the European Prospective Investigation into Cancer and Nutrition (EPIC): an observational study. Lancet 361, 1496-1501.

Birkett A, Muir J, Phillips J, Jones G \& O’Dea K (1996) Resistant starch lowers fecal concentrations of ammonia and phenols in humans. Am J Clin Nutr 63, 766-772.

Birkett AM, Jones GP, De Silva AM, Young GP \& Muir JG (1997) Dietary intake and faecal excretion of carbohydrate by Australians: importance of achieving stool weights greater than $150 \mathrm{~g}$ to improve faecal markers relevant to colon cancer risk. Eur J Clin Nutr 51, 625-632.

Burkitt DP (1969) Related disease-related causes? Lancet 2, 1299-1331.

Burkitt DP, Walker ARP \& Painter NS (1972) Effect of dietary fibre on stools and transit-times, and its role in the causation of disease. Lancet 2, 1408-1412.

Clark R \& Johnson S (2002) Sensory acceptability of foods with added lupin (Lupinus angustifolius) kernel fiber using pre-set criteria. J Food Sci 67, 356-362. 
Cook SI \& Sellin JH (1998) Review article: short chain fatty acids in health and disease. Aliment Pharmacol Ther 12, 499-507.

Cummings JH (1986) The effect of dietary fiber on fecal weight and composition. In Handbook of Dietary Fiber in Human Nutrition, pp. 211-281 [GA Spiller, editor]. Boca Raton, FL: CRC Press.

Cummings JH, Beatty ER, Kingman SM, Bingham SA \& Englyst HN (1996) Digestion and physiological properties of resistant starch in the human large bowel. Br J Nutr 75, 733-747.

Cummings JH, Bingham SA, Heaton KW \& Eastwood MA (1992) Fecal weight, colon cancer risk, and dietary intake of nonstarch polysaccharides (dietary fiber). Gastoenterology 103, 1783-1789.

Cummings JH \& Branch WJ (1986) Fermentation and production of short-chain fatty acids in the human large intestine. In Dietary Fibre: Basic and Clinical Aspects, pp. 131-149 [GV Vahouny and D Kritchevsky, editors]. New York: Plenum Press.

Cummings JH \& Macfarlane GT (1991) The control and consequences of bacterial fermentation in the human colon. J Appl Bacteriol 70, 443-459.

Cummings JH \& Macfarlane GT (1997) Colonic microflora: nutrition and health. Nutrition 13, 476-478.

Demigne C, Morand C, Levrat M-A, Besson C, Moundras C \& Remesy C (1995) Effect of propionate on fatty acid and cholesterol synthesis and on acetate metabolism in isolated rat hepatocytes. $\mathrm{Br}$ J Nutr 74, 209-219.

Di Giorgio J (1974) Nonprotein nitrogenous constituents. In Clinical Chemistry. Principles and Techniques, [RJ Henry and JW Winkelman, editors]. New York: Harper and Row.

Flood A, Velie EM, Chaterjee N, Subar AF, Thompson FE, Lacey JV, Schairer C, Troisi R \& Schatzkin A (2002) Fruit and vegetable intakes and the risk of colorectal cancer in the Breast Cancer Detection Demonstration Project follow-up cohort. Am J Clin Nutr 75, 936-943.

Fredstrom SB, Lampe JW, Jung HJG \& Slavin JL (1994) Apparent fibre digestibility and fecal short-chain fatty acid concentrations with ingestion of two types of dietary fiber. JPEN J Parenter Enteral Nutr 18, 14-19.

Fuchs CS, Giovannucci EL, Colditz GA, Hunter DJ, Stampfer MJ, Rosner B, Speizer FE \& Willett WC (1999) Dietary fiber and the risk of colorectal cancer and adenoma in women. $N$ Engl J Med 340, 169-176.

Gill CIR \& Rowland IR (2002) Diet and cancer: assessing the risk. $\mathrm{Br}$ J Nutr 88, S73-S87.

Gråsten SM, Juntunen KS, Poutanen KS, Gylling HK, Miettinen TA \& Mykkänen HM (2000) Rye bread improves bowel function and decreases the concentrations of some compounds that are putative colon cancer risk markers in middle-aged women and men. $J$ Nutr 130, 2215-2221.

Guillon F \& Champ MM (2002) Carbohydrate fractions of legumes: uses in human nutrition and potential for health. Br J Nutr 88, Suppl. 3, S293-S306.

Hague A, Elder DJ, Hicks DJ \& Paraskeva C (1995) Apoptosis in colorectal tumour cells: induction by the short chain fatty acids butyrate propionate and acetate and by the bile salt deoxycholate. Int $J$ Cancer 60, 400-406.

Hall RS, Johnson SK, Baxter AL \& Ball MJ (2005) Lupin kernel fibre enriched foods beneficially modify serum lipids in men. Eur J Clin Nutr 59, 325-333.

Jenab M, Rickard SE, Orcheson LJ \& Thompson LU (1999) Flaxseed and lignans increase cecal $\beta$-glucuronidase activity in rats. Nutr Cancer 33, 154-158.

Jenkins DJA, Vuksan V, Kendall CWC, Würsch P, Jeffcoat R, Waring S, Mehling CC, Vidgen E, Augustin LSA \& Wong E (1998) Physiological effects of resistant starches on fecal bulk, short chain fatty acids, blood lipids and glycemic index. J Am Coll Nutr 17, 609-616.

Johnson SK \& Gray DM (1993) Ingredients derived from lupin strong potential for a range of dietary fibre applications. Int Food Ingredients 5, 18-23.
Lin HC \& Visek WJ (1991) Large intestinal pH and ammonia in rats: dietary fat and protein interactions. J Nutr 121, 832-843.

Lupton JR (2000) Is fibre protective against colon cancer? Where the research is leading us. Nutrition 16, 558-561.

MacDonald IA, Webb GR \& Mahony D (1978) Fecal hydroxysteroid deydrogenase activities in vegetarian seventh-day adventists, control subjects and bowel cancer patients. Am J Clin Nutr 31, S233-S238.

Malhotra SL (1982) Fecal urobilinogen levels and $\mathrm{pH}$ of stools in population groups with different incidence of cancer of the colon, and their possible role in its aetiology. J $R$ Soc Med 75, 709-714.

McIntosh GH, Noakes M, Royle PJ \& Foster PR (2003) Whole-grain rye and wheat foods and markers of bowel health in overweight middle-aged men. Am J Clin Nutr 77, 967-974.

Nordgaard I, Mortnesen PB \& Langkilde A (1995) Small intestinal malabsorption and colonic fermentation of resistant starch and resistant peptides to short-chain fatty acids. Nutrition 11, 129-137.

O'Donnell LJ, Virjee J \& Heaton KW (1990) Detection of pseudodiarrhoea by simple clinical assessment of intestinal transit rate. Br Med J 300, 439-440.

Peters U, Sinha R, Chatterjee N, et al. (2003) Dietary fibre and colorectal adenoma in a colorectal cancer early detection programme. Lancet 361, 1491-1495.

Petterson DS (1998) Composition and food uses of lupins. In Lupins as Crop Plants: Biology, Production and Utilization, pp. 353-384 [JS Gladstones, CA Atkins and J Hamblin, editors]. Wallingford: CAB International.

Phillips J, Muir JG, Birkett A, Lu ZX, Jones GP, O’Dea K \& Young GP (1995) Effect of resistant starch on fecal bulk and fermentationdependent events in humans. Am J Clin Nutr 62, 121-130.

Pietinen P, Malila N, Virtanen M, Hartman TJ, Tangrea JA, Albanes D \& Virtamo J (1999) Diet and risk of colorectal cancer in a cohort of Finnish men. Cancer Causes Control 10, 387-396.

Silvester KR, Bingham SA, Pollock JRA, Cummings JH \& O'Neill IK (1997) Effect of meat and resistant starch on fecal excretion of apparent $\mathrm{N}$-nitroso compounds and ammonia from the human large bowel. Nutr Cancer 29, 13-23.

Silvester KR, Englyst HN \& Cummings JH (1995) Ileal recovery of starch from whole diets containing resistant starch measured in vitro and fermentation of ileal effluent. Am J Clin Nutr 62, 403-411.

Smith SC, Choy R, Hall RS, Johnson SK, Widerboer-Veloo AC \& Welling $\mathrm{G}$ (2005) Lupin kernel fibre consumption modifies faecal microbiota in men using 16S rRNA fluorescent in situ hybridisation. In Proceedings of the 38th Annual Australian Institute of Food Science \& Technology Convention. Alexandria, NSW, Australia: ALFST.

Thornton JR (1981) High colonic pH promotes colorectal cancer. Lancet 1, 1081-1083.

Turnbull CM, Baxter AL \& Johnson SK (2005) Water binding capacity and viscosity of Australian sweet lupin kernel fibre under in vitro conditions simulating the human upper gastrointestinal tract. Int J Food Sci Nutr 56, 87-94.

Visek WJ (1978) Diet and cell growth modulation by ammonia. Am J Clin Nutr 31, S216-S220.

Weber FL Jr, Banwell JG, Fresard KM \& Cummings JH (1987) Nitrogen in fecal bacterial, fiber, and soluble fractions of patients with cirrhosis: effects of lactulose and lactulose plus neomycin. $J$ Lab Clin Med 110, 259-263.

Wolever TMS, Fernandes J \& Rao AV (1996) Serum acetate: propionate ratio is related to serum cholesterol in men but not women. $J$ Nutr 126, 2790-2797.

Wolever TMS, Spadafora PJ, Cunnane SC \& Pencharz PB (1995) Propionate inhibits incorporation of colonic $\left[1,2-{ }^{13} \mathrm{C}\right]$ acetate into plasma lipids in humans. Am J Clin Nutr 61, 1241-1247.

Wrick KL, Robertson JB, Van Soest PJ, Lewis BA, Rivers JM, Roe DA \& Hackler LR (1983) The influence of dietary fiber source on human intestinal transit and stool output. $J$ Nutr 113, 1464-1479. 